\title{
$\mathrm{H}_{2}$ Plazma Ön İşleminden sonra Anodik Oksidasyon Uygulanmış Ti6Al4V Alaşımının Elektrokimyasal Korozyon Davranışının İncelenmesi
}

\author{
Yusuf KAYALI ${ }^{1}$, Şükrü TALAŞ ${ }^{1}$, YıImaz YALÇIN ${ }^{1}$, Ceylan TAŞKIN ${ }^{2}$ \\ ${ }^{1}$ Afyon Kocatepe Üniversitesi, Teknoloji Fakültesi, Metalurji ve Malzeme Mühendisliği Bölümü, Türkiye. \\ ${ }^{2}$ Afyon Kocatepe Üniversitesi, Fen Bilimler Enstitüsü, Türkiye. \\ e-posta: ykayali@aku.edu.tr
}

Geliş Tarihi: 04.07.2017 ; Kabul Tarihi: 19.12.2017

Özet

Çalışmada, $\varnothing 16 \mathrm{~mm}$ çapında ve $6 \mathrm{~mm}$ kalınlığında Ti6Al4V alaşımı (Grade 5) numune kullanılmıştır. Yüzeyleri metalografik olarak hazırlanan numuneler ultrasonik banyoda alkol ile temizlenerek yüzey işlemine uygun hale getirilmişlerdir. $\mathrm{H}_{2}$ plazma ön işleminden sonra Anodik oksidasyon işlem için elektrolit olarak 0,15 M Hidroflorik asit, \%0.3 $\mathrm{NH}_{4} \mathrm{~F}$ ve \%2 $\mathrm{H}_{2} \mathrm{O}$ içeren Etilen Glikol, $1 \mathrm{M} \mathrm{H}_{2} \mathrm{SO}_{4}$ (Sülfürik

Anahtar kelimeler

Ti6Al4V alaşımı; Anodik oksidasyon; SBF;

Elektrokimyasal korozyon.
Asit) ve $1 \mathrm{M} \mathrm{H}_{3} \mathrm{PO}_{4}$ (Fosforik Asit) çözeltileri kullanılmış ve işlemler 2 farklı voltaj seviyesi ( $20 \mathrm{~V}$ ve $120 \mathrm{~V}$ ) ve 60 dakika oksidasyon süresinde gerçekleştirilmiştir. Elektrokimyasal korozyon deneyleri SBF (simule Body Fluid) çözeltisinde 1 saat bekletme süresinde gerçekleştirilmiştir. Anodik oksidasyon işlemi uygulanan numunelerin yüzeyinin korozyon özelliklerinin belirlenmesi için Tafel Ekstrapolarizasyon ve Lineer Polarizasyon metodları, yüzeyin karakterizasyonu için X-ışınları ve Taramalı elektron mikroskobu (SEM) kullanılmıştır. Taramalı elektron mikroskobu, Ti6Al4V alaşım yüzeyinde Etilen Glikol (EG) çözeltisinde nano tüp formunda oksitlerin, 0,15 M Hidroflorik asit (HF) çözeltisinde ise gözenekli oksitlerin oluştuğu gözlenmiştir. Elektrokimyasal deneyler sonucunda, uygulanan voltajın artmasıyla, SBF çözeltisinde numunelerin korozyon direncinin azaldığı tespit edilmiştir.

\section{Investigation of Electrochemical Corrosion Behavior Of Anodic Oxidized Ti6Al4V Alloy After $\mathrm{H}_{2}$ Plasma Pretreatment}

\begin{abstract}
In the study, Ti6Al4V alloy (Grade 5) samples with a diameter of $16 \mathrm{~mm}$ and a thickness of $6 \mathrm{~mm}$ were used. The specimens whose surfaces were prepared metallographically were cleaned with ultrasonic bath alcohol and made suitable for surface treatment. After $\mathrm{H}_{2}$ plasma pretreatment, Ethylene Glycol, $1 \mathrm{M} \mathrm{H} 2 \mathrm{SO} 4$ (Sulfuric Acid) and 1M H3PO4 (Phosphoric Acid) solutions containing $0.15 \mathrm{M}$ Hydrofluoric acid, $0.3 \% \mathrm{NH} 4 \mathrm{~F}$ and $2 \% \mathrm{H} 2 \mathrm{O}$ were used as electrolytes for the anodic oxidation process and the treatments were carried out at 2 different voltage levels of $20 \mathrm{~V}$ and $120 \mathrm{~V}$ with a standard duration of and 60 minutes. Electrochemical corrosion experiments were carried out in SBF (simule Body Fluid) solution for 1 hour. Tafel Extrapolarization and Linear Polarization methods were used to determine the corrosion characteristics of the surface of the samples subjected to anodic oxidation, $\mathrm{X}$-rays and scanning electron microscopy (SEM) were used for surface characterization. Scanning electron microscopy revealed formation of nano-tube oxides in the ethylene glycol (EG) solution and porous oxides in the $0.15 \mathrm{M}$ hydrofluoric acid (HF) solution on the Ti6Al4V alloy surface. As a result of the electrochemical experiments, it was found that the corrosion resistance of the samples decreased in the SBF solution by increasing the applied voltage.
\end{abstract}

Keywords

Ti6Al4V Alloy; Anodic

Oxidized; Simule Body

Fluid; Electrochemical

Corrosion. 


\section{Giriş}

Titanyum, minimal doku reaksiyonu için biyomedikal ve diş implantlarında başarılı bir şekilde kullanılmaktadır. Bu alanlarda kullanılması, titanyumun doğal olarak oluşturduğu ince, yoğun, koruyucu olan oksit filmine (1,5-10 nm kalınlıkta özellikle $\mathrm{TiO}_{2}$ ) bağlıdır (Xiaolong et al. 2001, Lee et al. 2000). Bu oksit filmi termodinamik olarak çok kararlı olmasına rağmen, implant yüzeyini çevreleyen vücut sıvısı ile arasında reaksiyonlar, esas olarak malzemenin yüzey enerjisi, kompozisyonu, yapısı, pürüzlülüğü, topografisi ve çevresel sıvı koşulları (Xiaolong et al. 2001, Lee et al. 2000) gibi yüzey özellikleri tarafından belirlenir. Titanyum ve alaşımlarının biyo uyumluluklarını optimize etmek için son on yılda birçok çalışmalar yapılmıştır (Karlsson 2004, Ratner 2001).

Biyomalzeme olarak kullanılan titanyumun biyo uyumluluğunu arttırmaya yönelik ihtiyacı karşılamak üzere, Plazma sprey, Sol-jel, Anodik plazma kimyasal işlem ve Potansiyostatik anodik oksidasyon yöntemleri son yıllarda uygulanmaktadır (Neide et al. 2007). Anodik oksidasyon işlemi, oluşturulan elektrik alanla birlikte metal ve oksijen iyonlarının difüzyonu yöntemiyle yüzeyinin kaplanması istenilen metalin anot tarafına yerleştirilmesiyle yüzeyde oksit filminin oluştuğu elektroliz reaksiyonlarına denir (Sıcakyüz 2007, Albayrak 2008). Titanyumun anodik oksidasyon işlemiyle yüzeyde oluşturulan oksit filmi malzemenin aşınma direncini, korozyon direncini, yüzey pürüzlülüğünü ve biyouyumluluğu arttırıcı bir rol oynamaktadır (Sıcakyüz 2007). Ti6AI4V alaşımının vücut sıvısı ile olan etkileşimleri çeşitli çalışmalarda gösterilmiş olup, genel olarak, Ti6Al4V alaşımının vücut sıvılarına karşı iyi bir performans gösterdiği görülmektedir. Özellikle, protein takviyesi yapılan vücut sıvılarında $\mathrm{Ti}$ ve alaşımları paslanmaz çeliğe göre daha iyi peformans göstermiş (Reclaru and Meyer 1998) ve korozyon deneyleri sonucunda paslanmaz çeliğin daha zararlı metal iyonları vücut sıvısına yaydığı görülürken Ti6Al4V alaşımının korozyon peformasında bir değişme olmamıştır (Arslan et al 2008). Korozyon çifti çalışmalarında da Ti6Al4V alaşımı ile altın çifti en iyi peformansı göstererek implant malzemesi olarak kullanımı için ideal aday olduğu ortaya çıkmıştır (Songür et al 2009).

Bu çalışmada, $\mathrm{H}_{2}$ spater ön işlemi yapıldıktan sonra Etilen Glikol, $0.15 \mathrm{M} \mathrm{HF}, 1 \mathrm{M} \mathrm{H}_{2} \mathrm{SO}_{4}$ ve $1 \mathrm{M} \mathrm{H}_{3} \mathrm{PO}_{4}$ çözeltileri içinde anodik oksidayon işlemi yapılan titanyum alaşımının SBF çözelti içerisindeki elektrokimyasal yöntemle korozyon davranışları incelenmiştir.

\section{DENEYSEL ÇALIŞMALAR}

\subsection{Malzeme ve Anodik Oksidasyon Işlemi}

Bu çalışmada, kimyasal kompozisyonu Çizelge 1'de verilen Ti6Al4V (Grade2) kullanılmıştır. Yüzey işlemlerinden önce $\varnothing 10 \mathrm{~mm}$ çapında, $15 \mathrm{~mm}$ kalınlığında işlenen deney numuneleri 600, 800, 1000 ve 1200 mesh SiC zımparalar ile kaba parlatmaya tabi tutulmuş ve yüzey alkolle kurutulmuştur.

Çizelge 1. Ti6Al4V alaşımının (\%) kimyasal bileşimleri

\begin{tabular}{cccccccc}
\hline $\begin{array}{c}\text { Taban } \\
\text { Malzeme }\end{array}$ & \%Ti & \%Al & \%V & \%Fe & \%Ni & \%Si & \%Mn \\
\hline Ti6Al4V & 89,5 & 6,2 & 4,2 & 0,14 & 0,04 & 0,02 & 0,01 \\
\hline
\end{tabular}

Metalografik olarak hazırlanan numuneler ön işlem uygulamak için alkol ile yıkanıp kurutma işlemine tabi tutulur ve ön işleme hazır hale getirildi. Ön işleminde Ti6Al4V numuneler plazma cihazının vakum haznesinin içerisine yerleştirilerek hazne yaklaşık $2.10^{-2}$ mbar vakumda gerçekleştiridi. $\mathrm{H}_{2}$ plazma ön işlemi yaklaşık $200{ }^{\circ} \mathrm{C}$ 'de 30 dakika süresince ve 5 mbar işlem basıncında gerçekleştirilmiştir (Şekil 1a). Anodizasyon işlemi Şekil 1b'de şematik olarak gösterilen, laboratuar şartlarında üretilen anodizasyon hücresinde gerçekleştirilmiştir. Anodizasyon sistemi; soğutma banyosu ve soğutma banyosuna plastik borularla bağlanmış, içinde soğutma suyunun dolaştığı 1000 ml'lik bir cam beher kullanılmaktadır. Mervesan tarafından üretilmiş 305DII serisi 0-30V/0-5A doğru akım güç kaynağı ve manyetik karıştırıcıdan meydana gelmektedir. Anodik oksidasyon işlemi için elektrolit olarak 0,15 M HF, \% $0.3 \mathrm{NH}_{4} \mathrm{~F}+\% 2 \mathrm{H}_{2} \mathrm{O}$

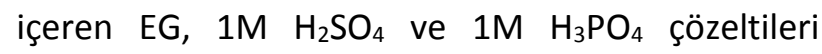
kullanılmış ve işlemler 2 farklı voltaj seviyesi ( $20 \mathrm{~V}$ ve 
120 V) ve 60 dakika oksidasyon süresinde gerçekleştirilmiştir.
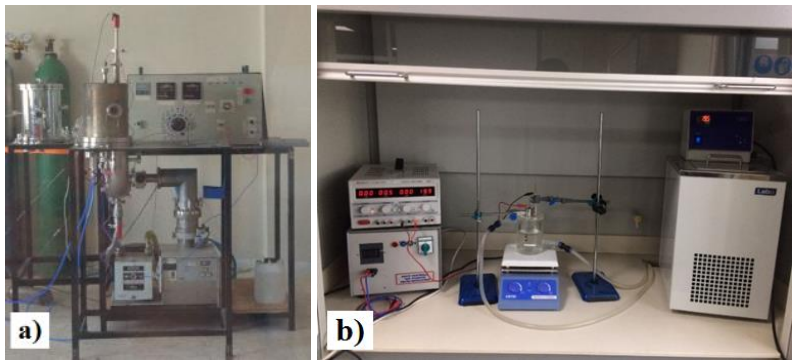

Şekil 1. a) $\mathrm{H}_{2}$ plazma ön işleminin gerçekleştirildiği deney düzeneği, b) Anodik oksidasyon prosesi.

\subsection{Elektrokimyasal Korozyon Testleri}

$0,15 \mathrm{M}$ Hidroflorik asit, \%0.3 $\mathrm{NH}_{4} \mathrm{~F}+\% 2 \mathrm{H}_{2} \mathrm{O}$ içeren Etilen Glikol, $1 \mathrm{M} \mathrm{H}_{2} \mathrm{SO}_{4}$ ve $1 \mathrm{M} \mathrm{H}_{3} \mathrm{PO}_{4}$ çözeltilerinde 2 farklı voltaj seviyesi ( $20 \mathrm{~V}$ ve $120 \mathrm{~V}$ ) ve 60 dakika anodik oksidasyon işlemi yapılmış olan titanyum alaşımlarının Elektrokimyasal korozyon deneyleri SBF, elektrokimyasal korozyon deneyleri Gamry referance 600 potansiyostat/galvanostat ZRA ve echem analyst soft programı ile gerçekleştirilmiştir. Elektrokimyasal korozyon deneylerine başlamadan önce $35^{\circ} \mathrm{C}^{\prime}$ de $15 \mathrm{dk}$ Aseton, $15 \mathrm{dk}$ Etanol ve $15 \mathrm{dk}$ çift distile edilmiş su ile ultrasonik olarak temizlenerek $40{ }^{\circ} \mathrm{C}^{\prime}$ de Etüv de bekletilerek kurutulmuştur. Elde edilen akım yoğunluğupotansiyel eğrilerinden, korozyon hızı, polarizasyon direnci (Rp), korozyon akımı ( $\mathrm{I}_{\text {cor }}$ ), korozyon hızı değerleri tespit edilmiştir. Daha sonra korozyon akımının yüzey alanına bölünerek korozyon akım yoğunluğu (i $\left.i_{c o r r}\right)$ bulunmuştur.

\section{DENEYSEL SONUÇLAR}

\subsection{Kaplama Tabakası ve Mikroyapı}

Biyolojik sıvı veya doku ile sağlıklı bir bağ için $\mathrm{TiO}_{2}$ nanotüpleri kullanılmaktadır. Çalışmada titanyum alaşımının yüzeyine 4 farklı çözeltide anodik işlem ile $\mathrm{TiO}_{2}$ nanotüpleri oluşturulmaya çalışılmıştır. Aşağıdaki Şekil 2 ve Şekil 3 de $\mathrm{H}_{2}$ spater ön işlemi yapılmış ve ön işlemsiz numunelerin Etilen glikol çözeltisinde $20 \mathrm{~V}$ ve $120 \mathrm{~V}$ da yapılan anodizasyon işlemi sonucunda oluşan $\mathrm{TiO}_{2}$ nanotüpler görülmektedir.
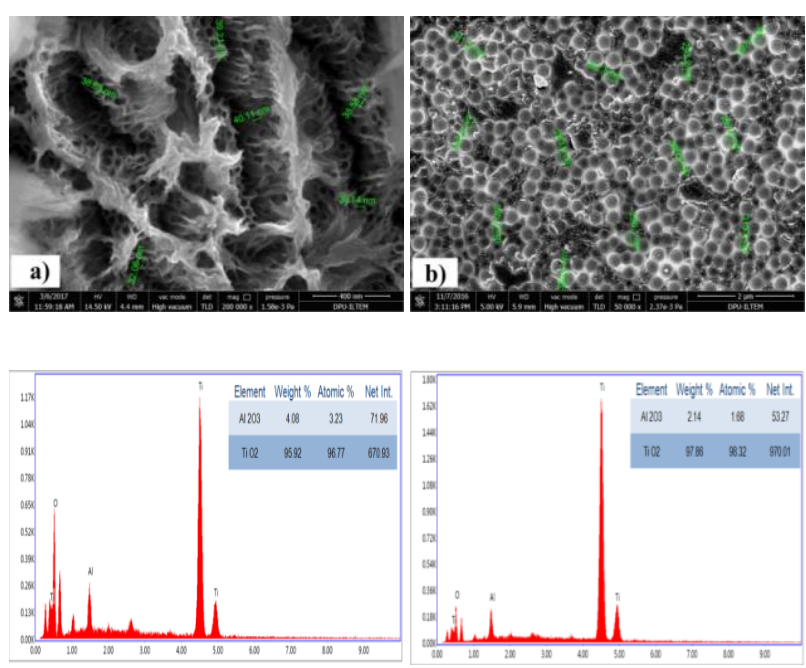

Şekil 2. a) $H_{2}$ spater ön işlemi uygulanan, b) Ön işlemsiz numunelerin 20V-60 dk Etilen Glikol çözeltisinde Anodizasyon işlemi sonrası SEM ve EDX analizleri.

$\mathrm{H}_{2}$ ön işlemli numunenin oluşan nanotüp çapları ortalama $35.78 \mathrm{~nm}$ iken işlemsiz numunenin ise 296.37 nm'dir. Normal numuneye uygulanan anodik oksidasyon sonucunda nanotüpleri büyük ve hafif düzenli iken $\mathrm{H}_{2}$ ön işleminin uygulandığı numunede nanotüp çapları küçülürken şekilleri de bozulmuştur.

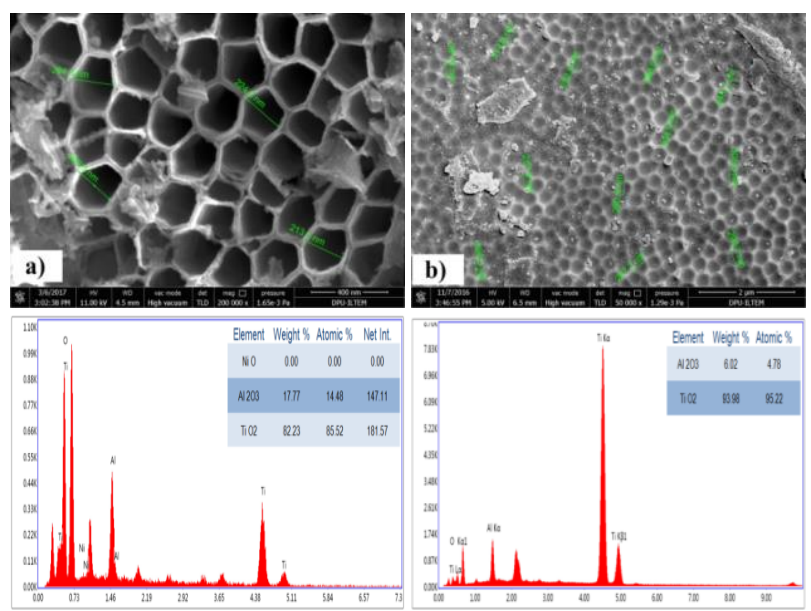

Şekil 3. a) $H_{2}$ spater ön işlemi uygulanan, b) Ön işlemsiz numunelerin 120 V 60 dk Etilen Glikol çözeltisinde anodizasyon işlemi sonrası SEM ve EDX analizleri.

Voltaj $120 \mathrm{~V}$ artırıldığında ise, $\mathrm{H}_{2}$ spater ön işlemli numunelerde oluşan nanotüp çapları ortalama 217.6nm iken işlemsiz numunenin ise 240.22 nm'dur. $120 \mathrm{~V}$ da $\mathrm{H}_{2}$ Ön işleminde nanotüp çapları ön işlemsizlere göre daha küçük ve daha düzenli bir görünümdedir. $20 \mathrm{~V}$ dan $120 \mathrm{~V}$ artması sonucunda $\mathrm{H}_{2}$ spater ön işlemli numunelerde oluşan $\mathrm{TiO}_{2}$ nanotüplerin çapında önemli bir artış olurken, ön 
işlemsizlerde önemli bir değişme olmamıştır (Demirel 2008, Giorgi et al. 2016).

Aşağıdaki Şekil 4 ve Şekil 5 de $\mathrm{H}_{2}$ spater ön işlemi yapılmış ve ön işlemsiz numunelerin Hidroflorik Asit çözeltisinde $20 \mathrm{~V}$ elde edilen $\mathrm{TiO}_{2}$ nanotüpler ve 120 $V$ ise da yapılan anodizasyon işlemi sonucunda oluşan $\mathrm{TiO}_{2}$ tabaka görülmektedir. Literatüre bakıldığında HF çözeltisinde düşük voltajlarda nanotüpler oluşmaktadır. Voltaj arttıkça nanotüpler bozulmakta ve oksit tabakasına dönüşmektedir (Kılınç et al. 2011, Özcan et al. 2017).
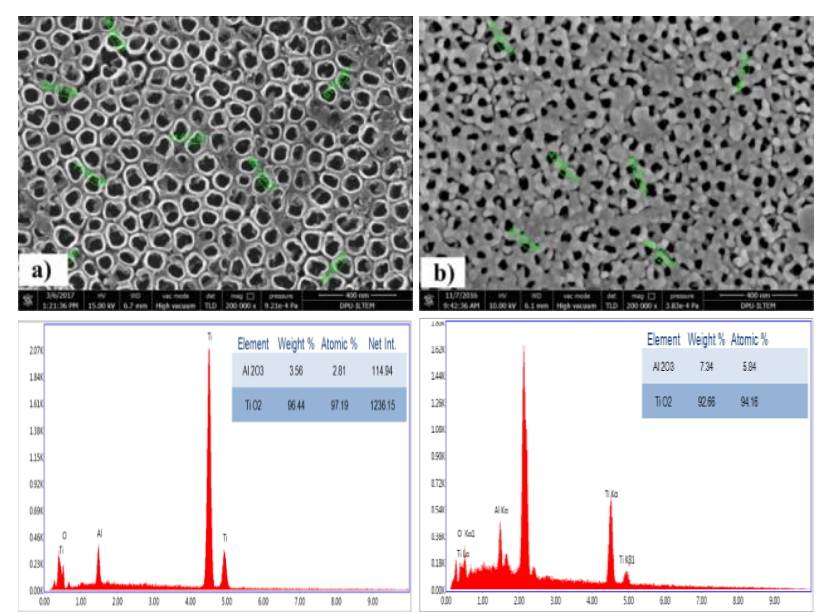

Şekil 4. a) $\mathrm{H}_{2}$ spater ön işlemi uygulanan, b) Ön işlemsiz numunelerin $20 \mathrm{~V} \quad 60 \mathrm{dk} 0.15 \mathrm{M}$ Hidroflorik Asit çözeltisinde anodizasyon işlemi sonrası SEM ve EDX analizleri.
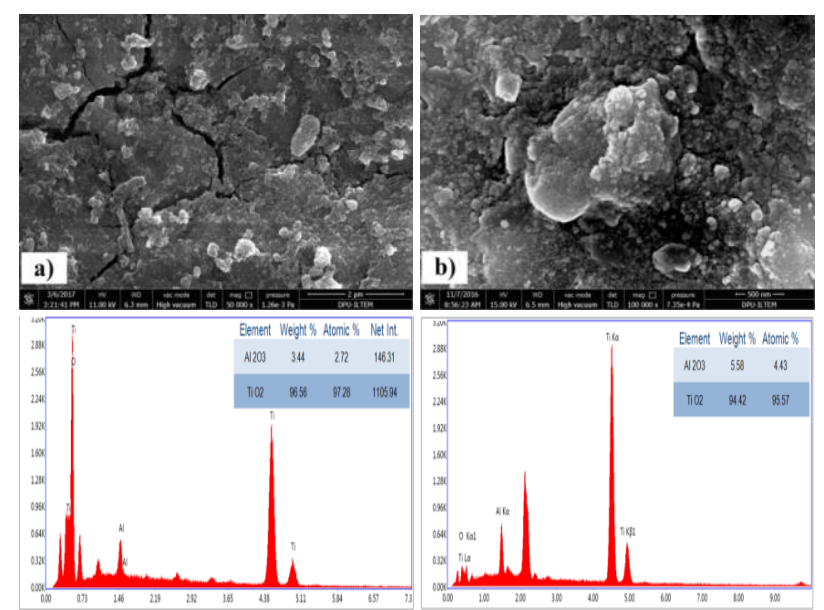

Şekil 5. a) $\mathrm{H}_{2}$ spater ön işlemi uygulanan, b) Ön işlemsiz numunelerin $120 \mathrm{~V} 60 \mathrm{dk} 0.15 \mathrm{M}$ Hidroflorik Asit çözeltisinde anodizasyon işlemi sonrası SEM ve EDX analizleri.

$\mathrm{H}_{2}$ ön işlemli numunenin oluşan nanotüp çapları ortalama $79.63 \mathrm{~nm}$ iken işlemsiz numunenin ise
$44.97 \mathrm{~nm}$ 'dir. İşlemsiz numuneye uygulanan anodik oksidasyonun bozulmaya başladığını ve $\mathrm{TiO}_{2}$ nanotüplerin çaplarının ön işlemsize göre düşük olduğu gözlemlenmektedir. $\mathrm{H}_{2}$ ön işlemi ile nanotüpler daha düzgün dağııımlı ve nanotüp çaplarının büyümesini sağlamıştır. Ancak voltajın artmasılyla nanotüp oluşumları bozulmuştur. Hidroflorik çözelti içerisinde $120 \mathrm{~V}$ da $\mathrm{TiO}_{2}$ nanotüp yerine $\mathrm{TiO}_{2}$ birikmesi olmuştur.

Şekil 6 ve Şekil 7 de $\mathrm{H}_{2}$ spater ön işlemi yapılmış ve ön işlemsiz numunelerin $\mathrm{H}_{2} \mathrm{SO}_{4}$ çözeltisinde $20 \mathrm{~V}$ ve $120 \mathrm{~V}$ da yapılan anodizasyon işlemi sonucunda $\mathrm{TiO}_{2}$ bir tabaka şeklinde bir oksit tabakası elde edilmiştir. Bu oksit tabakası $\mathrm{H}_{2}$ spater ön işlemi ile daha fazla olduğu SEM-EDX analizleri ile tespit edilmiştir. Aynı sonuçlar $\mathrm{H}_{3} \mathrm{PO}_{4}$ çözeltisinde yapılan anodizasyon işlemlerinde de elde edilmiştir (Şekil 8, Şekil 9). Şekil 7 incelendiğinde $120 \mathrm{~V}$ da nanotüplerin oluşmaya başladığı görülmektedir. Literatür incelemesinde $\mathrm{H}_{2} \mathrm{SO}_{4}$ çözeltisinde yüksek voltajlarda üzerinde nanotüplerin oluştuğu söylenmektedir (Yang et al. 2004).

Salantiuet. al. 0,25 $\mathrm{M} \mathrm{H}_{2} \mathrm{SO}_{4}$ çözeltisinde yaptıkları çalışmada $\mathrm{TiO}_{2}$ nanotüp elde edememişlerdir. Yüzeyde oluşan $\mathrm{TiO}_{2}$ tabaka şeklin de biriktiğini elde etmişlerdir. $\mathrm{Hem} \mathrm{H}_{2} \mathrm{SO}_{4}$ hem de $\mathrm{H}_{3} \mathrm{PO}_{4}$ çözeltilerinde nanotüp oluşumu gerçekleşmemektedir. Sadece Oksit tabakası oluşmaktadır. Bu oksit tabakasının kalınlığı artan voltaja göre farklılık göstermektedir (Simka et al. 2011, Sowa et al. 2014). Manjaiah ve Laubscher (2017) yaptıkları çalışmada farklı voltajlarda $\mathrm{H}_{2} \mathrm{SO}_{4}$ çözeltisi içerisinde anodizasyon işlemi gerçekleştirmişlerdir. Artan voltaj ile gözeneklerin arttığını tesbit etmişlerdir. Ancak $\mathrm{TiO}_{2}$ Nanotüp yerine bir oksit tabaka elde etmişleridir (Manjaiah and Laubscher 2017). 

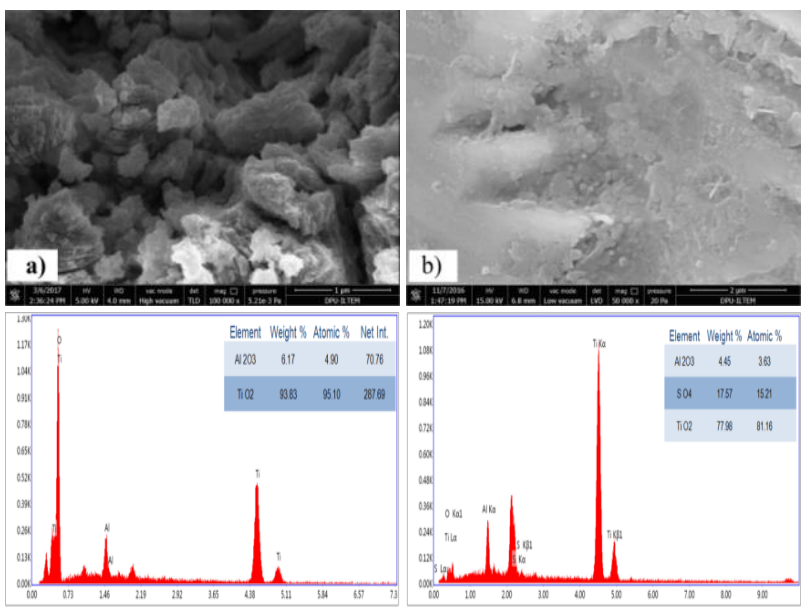

Şekil 6. a) $\mathrm{H}_{2}$ spater ön işlemi uygulanan, b) Ön işlemsiz numunelerin $20 \quad \mathrm{~V} \quad 60 \mathrm{dk} \quad 1 \mathrm{M}_{2} \quad \mathrm{H}_{2} \mathrm{SO}_{4}$ çözeltisinde anodizasyon işlemi sonrası SEM ve EDX analizleri.
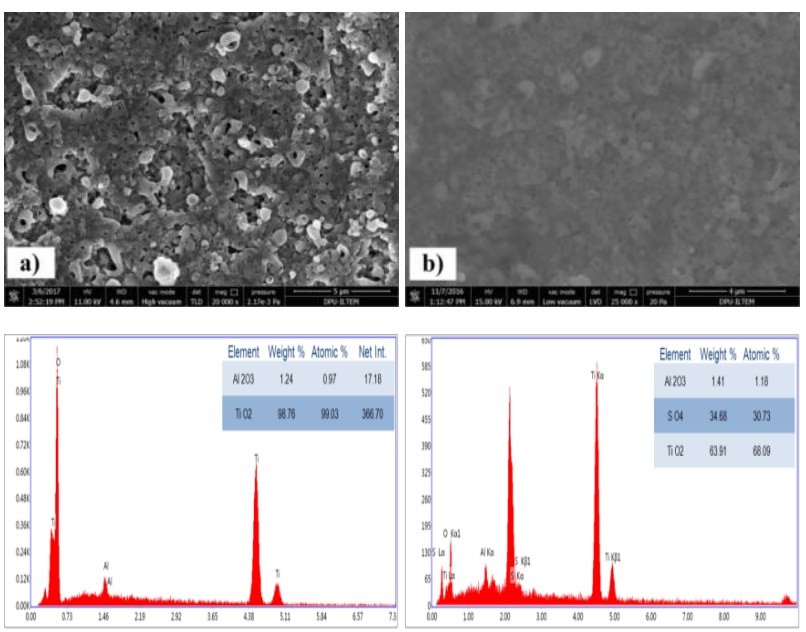

Şekil 7. a) $\mathrm{H}_{2}$ spater ön işlemi uygulanan, b) Ön işlemsiz numunelerin $120 \quad \mathrm{~V} \quad 60 \mathrm{dk} \quad 1 \mathrm{M}_{2} \mathrm{H}_{2} \mathrm{SO}_{4}$ çözeltisinde anodizasyon işlemi sonrası SEM ve EDX analizleri.
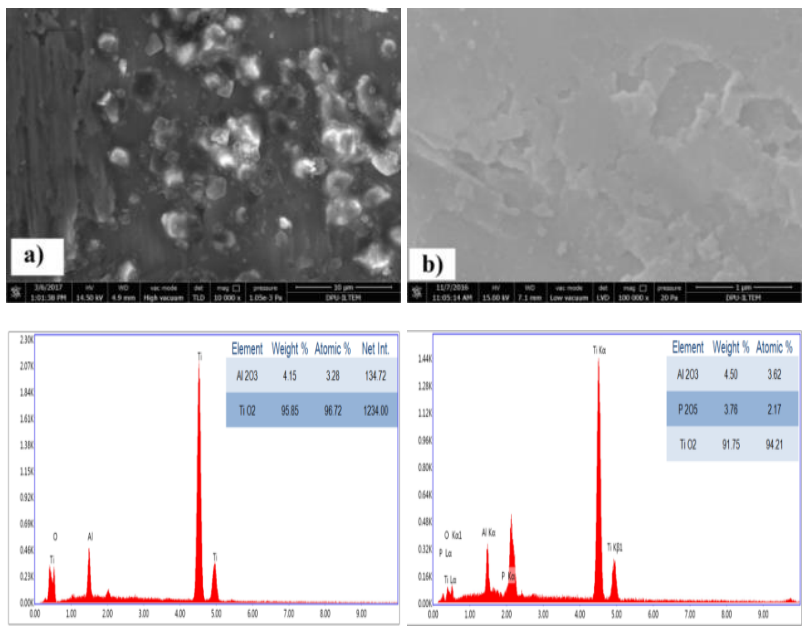

Şekil 8. a) $\mathrm{H}_{2}$ spater ön işlemi uygulanan, b) Ön işlemsiz numunelerin $20 \quad \mathrm{~V} \quad 60 \quad \mathrm{dk} \quad 1 \mathrm{M} \quad \mathrm{H}_{3} \mathrm{PO}_{4}$ çözeltisinde Anodizasyon işlemi sonrası SEM ve EDX analizleri.
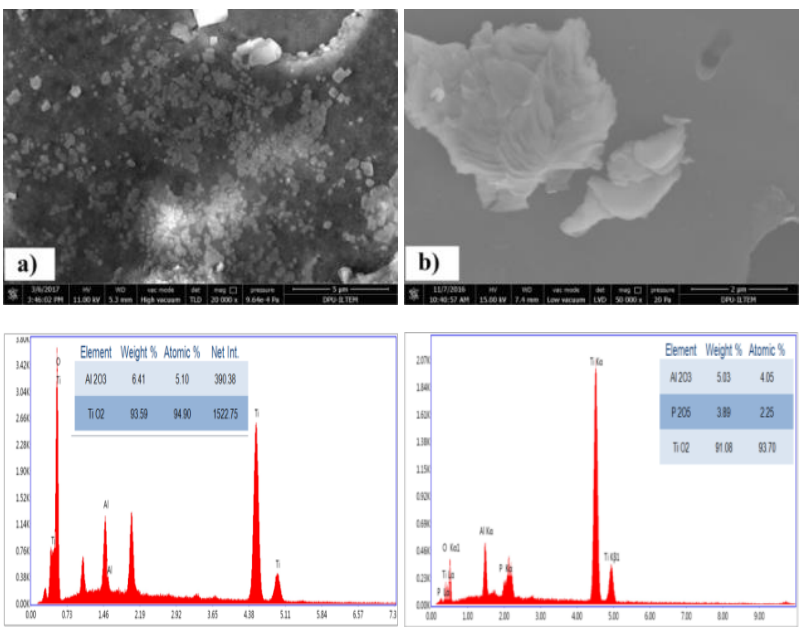

Şekil 9. a) $\mathrm{H}_{2}$ spater ön işlemi uygulanan, b) Ön işlemsiz numunelerin $120 \quad \mathrm{~V} \quad 60 \mathrm{dk} \quad 1 \mathrm{M} \mathrm{H}_{3} \mathrm{PO}_{4}$ çözeltisinde anodizasyon işlemi sonrası SEM ve EDX analizleri.

\subsection{Elektrokimyasal Korozyon Testleri}

\subsubsection{Tafel ve Lineer Polarizasyon Deney Sonuçları}

\subsubsection{1 Ön İslemsiz Numuneler}

Ön işlemsiz anodizasyon yapılmış Ti6Al4V alaşımının SBF ortamında 1 saat ve bekletme süreleri sonucunda Tafel ve lineer polarizasyon yöntemi ile elde edilen korozyon parametreleri Çizelge 2'da verilmiştir.

Çizelge 2. Ön işlemsiz Anodizasyon yapılmış Ti6Al4V alaşımının SBF ortamında elde edilen korozyon karakteristikleri.

\begin{tabular}{|c|c|c|c|c|c|}
\hline $\begin{array}{l}\text { Korozyon } \\
\text { Yapıldığı } \\
\text { Çözelti }\end{array}$ & $\begin{array}{c}\text { Anodik } \\
\text { Oksidasyon } \\
\text { Yapıldığı } \\
\text { Çözelti }\end{array}$ & $\begin{array}{l}\text { Deney } \\
\text { Metodu }\end{array}$ & $\begin{array}{l}\text { icorr. } \\
(\mu \mathrm{A} / \\
\left.\mathrm{cm}^{2}\right)\end{array}$ & $\begin{array}{c}\text { Korozyon } \\
\text { Hizı x10-3 } \\
\text { (mpy) }\end{array}$ & $\begin{array}{c}\mathrm{Rp} \\
(\mathrm{k} \Omega)\end{array}$ \\
\hline \multirow{9}{*}{ SBF } & & İşlemsiz & 1,460 & 407,5 & 105,7 \\
\hline & Etilen & $20 \mathrm{~V}-60 \mathrm{dk}$ & 0,165 & 46,04 & 205,8 \\
\hline & Glikol & $120 \mathrm{~V}-60 \mathrm{dk}$ & 0,921 & 256,1 & 118,7 \\
\hline & $0.15 \mathrm{M}$ & $20 \mathrm{~V}-60 \mathrm{dk}$ & 0,191 & 53,02 & 577,4 \\
\hline & $\begin{array}{l}\text { Hidroflorik } \\
\text { Asit }\end{array}$ & $120 \mathrm{~V}-60 \mathrm{dk}$ & 0,204 & 56,62 & 126,1 \\
\hline & \multirow{2}{*}{$1 \mathrm{M} \mathrm{H}_{2} \mathrm{SO}_{4}$} & $20 \mathrm{~V}-60 \mathrm{dk}$ & 0,327 & 90,86 & 340,5 \\
\hline & & $120 \mathrm{~V}-60 \mathrm{dk}$ & 3,660 & 1018 & 59,71 \\
\hline & \multirow{2}{*}{$1 \mathrm{M} \mathrm{H}_{3} \mathrm{PO}_{4}$} & $20 \mathrm{~V}-60 \mathrm{dk}$ & 0,164 & 45,52 & 596,6 \\
\hline & & $120 \mathrm{~V}-60 \mathrm{dk}$ & 0,277 & 77,02 & 328,8 \\
\hline
\end{tabular}

Ön işlemsiz anodizasyon yapılmış Ti6Al4V alaşımının SBF ortamında 1 saat bekletme süreleri sonucunda Tafel polarizasyon yöntemi ile elde edilen Tafel eğrileri Şekil 10'de verilmektedir. 

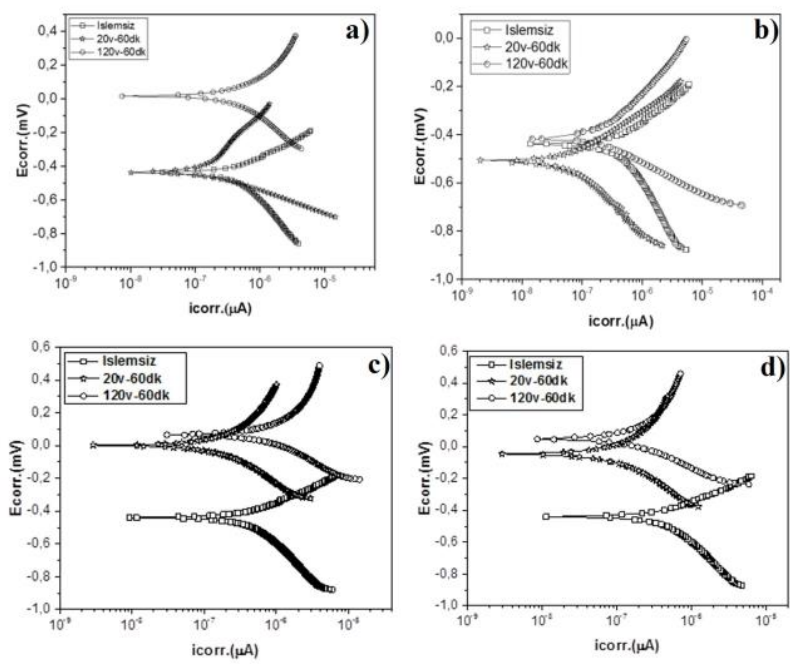

Şekil 10. a) Etilen Glikol, b) $0.15 \mathrm{M}$ Hidroflorik, c) $1 \mathrm{M}$ $\mathrm{H}_{2} \mathrm{SO}_{4}$ d) $1 \mathrm{M} \mathrm{H}_{3} \mathrm{PO}_{4}$ çözeltilerinde anodizasyon yapılmış Ti6Al4V alaşımının SBF ortamında 1 saat bekletilmiş numunelerin Tafel eğrileri.

Bütün çözeltilerde için de korozyon direnci bütün anodizasyon şartlarında işlemsiz numuneye göre iyileşmiştir. Sadece $\mathrm{H}_{2} \mathrm{SO}_{4}$ çözeltisinde $120 \mathrm{~V}$ da yapılan anodik oksidasyonda korozyon direnci kötü çıkmıştır. Korozyon dirençleri doğrudan oksit tabakasının yapısı ile ilişkilidir. Etilen Glikol çözeltisi ve $0.15 \mathrm{M}$ Hidroflorik asit çözeltilerin de $20 \mathrm{~V}$ potansiyele kadar anodize edilmiş numuneler daha soy duruma doğru yaklaşırken, $120 \mathrm{~V}$ potansiyelde anodize edilmiş numuneler de yüzeyinde oluşan gözenekli tabakadan dolayı korozon direnci daha kötüdür. Çünkü potansiyel artışı ile beraber yüzeyde gözenek miktarı artmaktadır (Albayrak 2008).

Her bir numunenin $i_{\text {corr }}$ ve Rp değerleri, sırasıyla, 0.165 ila $3.660 \mu \mathrm{A} / \mathrm{cm}^{2}$ ve 59.71-596.6 $\mathrm{k} \Omega$ arasında değişmektedir. Genel olarak, bütün çözeltide de işlemsiz numuneye göre, iyi bir korozyon direnci göstermiştir. En yüksek korozyon dirençleri Etilen Glikol ve $\mathrm{H}_{3} \mathrm{PO}_{4}$ çözeltisinde $20 \mathrm{~V}$ da yapılan anodizasyon işleminde elde edilmiştir. Ayrıca bütün çözeltide de anodizasyon voltajı arttıkça (20 V'dan 120 V'a) korozyon direnci düşmektedir. Anodizasyon yapılmış numuneler arasında en yüksek $i_{\text {corr }}$ değeri $3.660 \mu \mathrm{A} / \mathrm{cm}^{2}$ değeri ve en yüksek korozyon hızı $1018 \times 10^{-3} \mathrm{mpy}$ ile $\mathrm{H}_{2} \mathrm{SO}_{4}$ çözeltisinde $120 \mathrm{~V} \mathrm{da}$ anodizasyon işleminde elde edilmiştir. En düşük korozyon hızı $45.52 \times 10^{-3} \mathrm{mpy}$ değeri ile $\mathrm{H}_{3} \mathrm{PO}_{4}$ çözeltisinde $20 \mathrm{~V}$ da yapılan anodizasyon numunesinde elde edilmiştir.

Bu sonuçlar hem korozyon akım yoğunluğu değeri (i $\left.i_{c o r r}\right)$, hem de korozyon direnci (Rp) ile uyumludur.

\subsubsection{2 $\mathrm{H}_{2}$ Ön Işslem Yapılmış Numuneler}

H2 Ön işlem yapıldıktan sonra anodizasyon yapılmış Ti6Al4V alaşımının SBF ortamında 1 saat ve bekletme süreleri sonucunda Tafel ve lineer polarizasyon yöntemi ile elde edilen korozyon karakteristikleri Çizelge $3^{\prime}$ da verilmiştir.

Çizelge 3. $\mathrm{H}_{2}$ ön İşlem yapıldıktan sonra anodizasyon yapılmış Ti6AI4V alaşımının SBF ortamında elde edilen korozyon karakteristikleri.

\begin{tabular}{|c|c|c|c|c|c|}
\hline $\begin{array}{l}\text { Korozyon } \\
\text { Yapıldığı } \\
\text { Çözelti }\end{array}$ & $\begin{array}{c}\text { Anodik } \\
\text { Oksidasyon } \\
\text { Yapıldığı } \\
\text { Çözelti }\end{array}$ & $\begin{array}{l}\text { Deney } \\
\text { Metodu }\end{array}$ & $\begin{array}{l}\text { İcorr. } \\
(\mu \mathrm{A} / \\
\left.\mathrm{cm}^{2}\right)\end{array}$ & $\begin{array}{c}\text { Korozyon } \\
\text { Hizı x10-3 } \\
\text { (mpy) }\end{array}$ & $\begin{array}{c}\mathrm{Rp} \\
(\mathrm{k} \Omega)\end{array}$ \\
\hline \multirow{10}{*}{ SBF } & İşlemsiz & & 1,460 & 407,5 & 105,7 \\
\hline & $\begin{array}{l}\text { Sadece } \mathrm{H}_{2} \mathrm{Sp} \\
\text { Ön işlem yap }\end{array}$ & & 0,146 & 40,55 & 499,7 \\
\hline & \multirow{2}{*}{ Etilen Glikol } & $\begin{array}{l}20 \mathrm{~V}- \\
60 \mathrm{dk}\end{array}$ & 0,052 & 14,53 & 818,1 \\
\hline & & $\begin{array}{l}120 \mathrm{~V}- \\
60 \mathrm{dk}\end{array}$ & 0,029 & 8,191 & 1318 \\
\hline & \multirow{2}{*}{$\begin{array}{c}0.15 \mathrm{M} \\
\text { Hidroflorik } \\
\text { Asit }\end{array}$} & $\begin{array}{l}20 \mathrm{~V}- \\
60 \mathrm{dk}\end{array}$ & 0,047 & 12,97 & 331,1 \\
\hline & & $\begin{array}{l}120 \mathrm{~V}- \\
60 \mathrm{dk}\end{array}$ & 0,090 & 25,07 & 362,9 \\
\hline & \multirow{2}{*}{$1 \mathrm{M} \mathrm{H}_{2} \mathrm{SO}_{4}$} & $\begin{array}{l}20 \mathrm{~V}- \\
60 \mathrm{dk}\end{array}$ & 0,220 & 61,33 & 145,0 \\
\hline & & $\begin{array}{l}120 \mathrm{~V}- \\
60 \mathrm{dk}\end{array}$ & 1,100 & 304,8 & 34,83 \\
\hline & \multirow{2}{*}{$1 \mathrm{M} \mathrm{H}_{3} \mathrm{PO}_{4}$} & $\begin{array}{l}20 \mathrm{~V}- \\
60 \mathrm{dk}\end{array}$ & 0,104 & 28,94 & 295,3 \\
\hline & & $\begin{array}{l}120 \mathrm{~V}- \\
60 \mathrm{dk}\end{array}$ & 0,124 & 34,57 & 375,8 \\
\hline
\end{tabular}

Bütün çözeltilerde için de korozyon direnci bütün $\mathrm{H}_{2}$ spater ön işlem yapıldıktan sonra yapılan anodizasyon şartlarında, işlemsiz numuneye göre iyileşmiştir. Ancak sadece $\mathrm{H}_{2}$ spater ön işlemine tabi tutulan numunenin korozyon direnci, spater ön işlem yapıldıktan sonra $\mathrm{H}_{2} \mathrm{SO}_{4}$ çözeltisinde anodizasyon işlemi uygulanan numunelerin korozyon direnci kötüdür. Bunun sebebi $\mathrm{H}_{2} \mathrm{SO}_{4}$ çözeltisinde meydana gelen oksit tabakasının daha kalın olmasından dolayı koruyucu özelliğini kaybederek korumadığından olabilir.

Etilen Glikol hariç bütün çözeltilerde $20 \mathrm{~V}$ potansiyele kadar anodize edilmiş numuneler daha soy duruma doğru yaklaşırken, $120 \mathrm{~V}$ potansiyelde anodize edilmiş numuneler de yüzeyinde oluşan gözenekli tabakadan dolayı korozon direnci daha 
kötü olduğu hem akım yoğunluğu ile hem de korozyon direnciyle orantılı olduğu Çizelge 3 de görülmektedir. Bunun sebebi potansiyel artışı ile beraber yüzeyde gözenek miktarının artması ve koruyucu olan oksit tabakasının koruyucu özelliğini kaybetmesine bağlanabilir (Albayrak 2008).

$\mathrm{H}_{2}$ Ön işlem yapıldıktan sonra anodizasyon yapılmış Ti6Al4V alaşımının SBF ortamında 1 saat bekletme süreleri sonucunda Tafel polarizasyon yöntemi ile elde edilen Tafel eğrileri Şekil 11'de verilmektedir. $i_{\text {corr }}$ ve Rp değerleri, sırasıyla, 0.029 ila $1.100 \mu \mathrm{A} / \mathrm{cm}^{2}$ ve 34.83-1318 $\mathrm{k} \Omega$ arasında değişmektedir. Hiçbir işlem yapılmamış Ti6Al4V alaşımının korozyon direncinden, $\mathrm{H}_{2}$ spater ön işlemi yapıldıktan sonra anodizasyon işlemi uygulanan numunelerin korozyon dirençleri daha iyidir. Ayrıca sadece $\mathrm{H}_{2}$ spater ön işlemi ile bile korozyon hızı azalmıştır. Sadece $\mathrm{H}_{2}$ spater ön işlemi yapıldıktan sonra anodizasyon yapılmış numuneler arasında $\mathrm{H}_{2} \mathrm{SO}_{4}$ çözeltisindeki numunerin korozyon dirençleri sadece $\mathrm{H}_{2}$ sapater ön işlemi uygulanan numunelerin korozyon dirençlerinden kötüdür. En yüksek korozyon direncleri $\mathrm{H}_{2}$ spater ön işleminden sonra Etilen Glikol çözeltisinde $120 \mathrm{~V}$ da yapılan anodizasyon işleminde elde edilmiştir. Ayrıca Etilen Glikol çözeltisi hariç bütün çözeltide de anodizasyon voltajı arttıkça (20 V'dan 120 V'a) korozyon direnci düşmektedir.
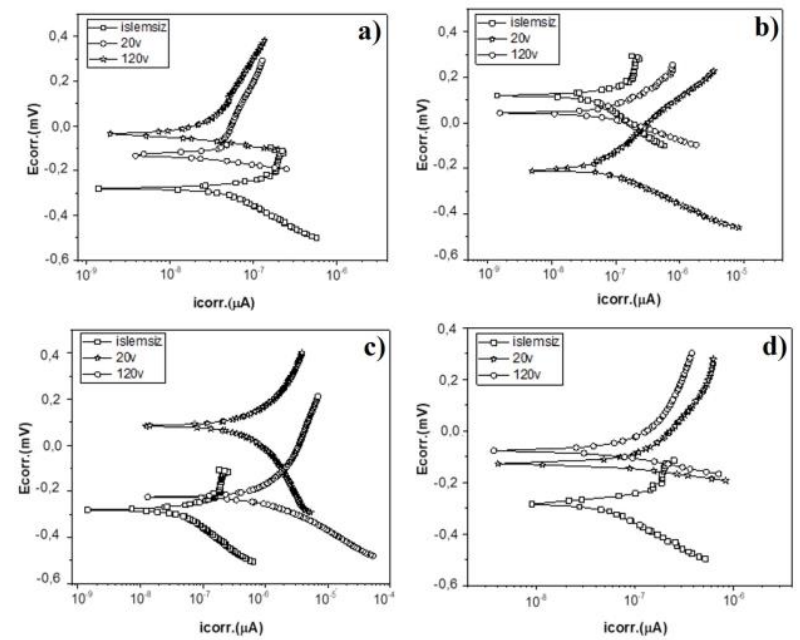

Şekil 11. $\mathrm{H}_{2}$ ön İşlem yapıldıktan sonra a) Etilen Glikol, b) $0.15 \mathrm{M}$ Hidroflorik, c) $1 \mathrm{M} \quad \mathrm{H}_{2} \mathrm{SO}_{4}$ d) $1 \mathrm{M} \quad \mathrm{H}_{3} \mathrm{PO}_{4}$ çözeltilerinde anodizasyon yapılmış Ti6Al4V alaşımının SBF ortamında 1 saat bekletilmiş numunelerin Tafel eğrileri.
$\mathrm{H}_{2}$ spater ön işleminden sonra anodizasyon yapılmış numuneler arasında en yüksek $\mathrm{i}_{\text {corr }}$ değeri 1.100 $\mu \mathrm{A} / \mathrm{cm}^{2}$ değeri ve en yüksek korozyon hızı $304.8 \times 10^{-}$ ${ }^{3} \mathrm{mpy}$ ile $\mathrm{H}_{2} \mathrm{SO}_{4}$ çözeltisinde $120 \mathrm{~V}$ da anodizasyon işleminde elde edilmiştir. En düşük korozyon hızı $8.191 \times 10^{-3} \mathrm{mpy}$ değeri ile Etilen Glikol çözeltisinde $120 \mathrm{~V}$ da yapılan anodizasyon numunesinde elde edilmiştir. Bu sonuçlar hem korozyon akım yoğunluğu değeri ( $\left.i_{\text {corr }}\right)$, hem de korozyon direnci (Rp) ile uyumludur.

\section{SONUÇLAR}

Biyolojik ortamlarda kullanılan titanyum impantlarının başarısı büyük oranda yüzey özelliklerine bağııdır. Vücuda yerleştirilen bir malzeme, vücut sıvıları ve diğer organlar ile çeşitli etkileşimlere maruz kalmaktadır. Vücuda yerleştirilen implant sonrasında hem implant hem de vücut etkileşmektedir. Titanyum implantların yüzey özelliklerinin değiştirilmesi ve geliştirilmesi gereksinimi bu nedenle ortaya çıkmaktadır. Günümüzde yüzey özelliklerini değiştirmek için yaygın olarak anodik oksidasyon yöntemi kullanılmaktadır.

Ti6Al4V alaşımının yüzeyinde Etilen Glikol ve Hidroflorik asit çözeltilerinde yapılan anodik oksidasyon işlemi ile $20 \mathrm{~V}$ ve $120 \mathrm{~V}$ voltajlarda $\mathrm{TiO}_{2}$ nanotüpleri oluşturulurken, $\mathrm{H}_{2} \mathrm{SO}_{4}$ ve $\mathrm{H}_{3} \mathrm{PO}_{4}$ çözeltilerinde $\mathrm{TiO}_{2}$ nanotüp yerine oksit tabakası elde edilmiştir.

Anodizasyon voltajının artışı ile Etilen glikol çözeltisinde nano tüplerin çapları artmıştır. Fakat $0.15 \mathrm{M}$ Hidroflorik asit içerisinde ise voltajın artmasıyla nanotüpler bozulmuştur.

Anodizasyon voltajının artmasıyla Nano tüp morfolojisi bozulmaktadır. Çalışma kapsamında 4 farklı çözeltide $\mathrm{H}_{2}$ plazma ön işleminin anodik oksidasyon uygulamasında çözeltiye göre farklılık gösterdiği tespit edilmiştir.

Hidroflorik asit çözeltisinde nanotüp çap büyüklüğü ve nanotüplerin düzenli dağılımı açısından olumlu yönde etkisi olurken başka çözeltide ise nanotüp çapı küçülmesi gibi olumsuz sonuçlar elde edilmiştir. 
Genel olarak, bütün çözeltide de işlemsiz numuneye göre, iyi bir korozyon direnci göstermiştir. En yüksek korozyon dirençleri Etilen Glikol ve $\mathrm{H}_{3} \mathrm{PO}_{4}$ çözeltisinde $20 \mathrm{~V}$ da yapılan anodizasyon işleminde elde edilmiştir. Ayrıca bütün çözeltide de anodizasyon voltajı arttıkça (20 V'dan 120 V'a) korozyon direnci düşmektedir.

$\mathrm{H}_{2}$ Spater ön işleminden sonra anodizasyon yapılmış numuneler arasında en yüksek $\mathrm{i}_{\text {corr }}$ değeri 1.100 $\mu \mathrm{A} / \mathrm{cm}^{2}$ değeri ve en yüksek korozyon hızı $304.8 \times 10^{-}$ ${ }_{3}^{3} \mathrm{mpy}$ ile $\mathrm{H}_{2} \mathrm{SO}_{4}$ çözeltisinde $120 \mathrm{~V}$ da anodizasyon işleminde elde edilmiştir. En düşük korozyon hızı $8.191 \times 10^{-3} \mathrm{mpy}$ değeri ile Etilen Glikol çözeltisinde $120 \mathrm{~V}$ da yapılan anodizasyon numunesinde elde edilmiştir.

\section{TEŞEKKÜR}

Bu çalışma için 16.TEKNOLOJi.ALTY.02 nolu projeyi destekleyen Afyon Kocatepe Üniversitesi, Bilimsel Araştırma Projeleri Komisyonuna teşekkür ederiz.

\section{KAYNAKLAR}

Albayrak, Ç., 2008. CP-Titanyumun Anodizasyonu, Yüksek Lisans Tezi, Atatürk Üniversitesi, Fen Bilimler Enstitüsü, Erzurum, 91.

Arslan, H., Çelikkan, H., Örnek, N., Ozan, O., Ersoy, A.E., Aksu, M.L., 2008. Galvanic corrosion of titaniumbased dental implant materials, Journal of Applied Electrochemistry, 38, 6, 853-859

Demirel, A., 2008. Gözenekli Titanyum Oksinitrür yapıların Anodik Oksidasyon Yolu ile Üretilmesi ve Karakterizasyonu, Yüksek Lisans, İstanbul Teknik Üniversitesi, Fen Bilimler Enstitüsü, İstanbul, 78.

Giorgi, L., Salernitano, E., Makris, T.H., Giorgi, R., Leoni, E., Grilli, M.L., Lisi, N., 2016. Titania nanotubes selfassembled by electrochemical anodization: Semiconducting andel ectrochemical properties, Thin Solid Films 601, 28-34.

Karlsson, M., 2004. Nano-porousalumina, a potential bone implantcoating, BMC, Husargatan 3, Uppsala, B42.

Kılınç, N., Şennik, E., Öztürk, Z.Z., 2011. Fabrication of TiO2 nanotubes by anodization of Ti thinfilmsfor VOC sensing, Thin Solid Films, 520, 953-958.

Lee, T.M, Chang, E.,Yang, C.Y., 2000. A comparison of the surface characteristic sandion release of Ti6Al4V and heat-treated Ti6Al4V, J. Biomed. Mater. Res., 50, 499511.
Manjaiah, M., Laubscher, R.F., 2017. Effect of anodizing on surfaceintegrity of Grade 4 titanium for bio medical applications, Surface\&Coatings Technology, 310, 263-272

Neide, K., Kuromoto, Renata A. Simão, Gloria A. Soar, 2007. Titanium oxide films produced on commercially pure titanium by anodic oxidation with differentvoltages Materials Characterization, 58, 2, 114-12.

Özcan, L., Yalçın, P., Alagöz, O., Yurdakal, S., 2017. Selective photoelectrocatalytic oxidation of 5(hydroxymethyl)-2-furaldehyde in water by using $\mathrm{Pt}$ loaded nanotube structure of $\mathrm{TiO}_{2}$ on Ti photoanodes, Catalysis Today, 281, 205-213.

Ratner, B.D., 2001. A Perspective on Titanium Bio compatibility, in: Brunette, D.M., Tengvall, P., Texor, M., Thmsen, P., (Eds.), Titanium in Medicine, Springer, Berlin, p. 2.

Reclaru, L., Meyer, J.M., 1994. Study of Corrosion between a Titanium Implant and Dental Alloys, Journal of Dentistry, 22, 3, 159-168

Sıcakyüz, Ö., 2007. Titanyum ve Titanyum alaşımlarının Anodik Oksidasyon Davranışı ve Karakterizasyonu. Yüksek Lisans Tezi, İstanbul Teknik Üniversitesi, Fen Bilimler Enstitüsü, İstanbul, 76.

Simka, W.,Sadkowski, A., Warczak, M., Iwaniak, A., Dercz, G., Michalska, J., Maciej, A., 2011,. Characterization of passivefilmsformed on titanium during anodic oxidation, Electrochimica Acta, 56, 8962-8968.

Songür, M., Çelikkan, H., Gökmeşe, F., Şimşek S.A., Altun, N.Ş., Aksu, M.L. 2009, Journal of Applied Electrochemistry, 39, 1259-1265

Sowa, M., Greń, K., Kukharenko, A.I., Korotin, D.M., Michalska, J., Warszyńska, L.S., Mosiałek, M., Żak, J., Pamuła, E., Kurmaev, E.Z., Cholakh, S.O., Simka, W., 2014. Influence of electropolishing and anodic oxidation on morphology, chemical composition and corrosion resistance of niobium, Materials Science and Engineering, 42, 529-537.

Xiaolong, Z.,Kyo-Han, K., Yongsoo, J., 2011. Anodic oxide films containing Caand $\mathrm{P}$ of titanium biomaterial, Biomaterials, 22, 2199-2206

Yang, B.,Uchida, M., Kim, H., Zhang, X., Kokubo, T., 2004. Preparation of bioactive titanium metal via anodic oxidation treatment, Biomaterials $25,1003-1010$. 